\title{
Influence of Ozonized Oil Nanoemulsions on B-16 Melanoma Cells: An in Vitro Study
}

\author{
Yeliz Yalçın1 ${ }^{(1)}$, Ishak Özel Tekin² (D), R. Seda Tığlı Aydın'1,3* (i) \\ ${ }^{1}$ Department of Nanotechnology Engineering, Zonguldak Bülent Ecevit University, Zonguldak, Turkey \\ ${ }^{2}$ Department of Immunology, Facultyof Medicine, ZonguldakBülent Ecevit University, Zonguldak, Turkey \\ ${ }^{3}$ Department of Biomedical Engineering, Zonguldak Bülent Ecevit University, Zonguldak, Turkey \\ Email: *rseda.tigli@gmail.com
}

How to cite this paper: Yalçın, Y., Tekin, I.Ö. and Aydın, R.S.T. (2021) Influence of Ozonized Oil Nanoemulsions on B-16 Melanoma Cells: An in Vitro Study. Journal of Biomaterials and Nanobiotechnology, 12, 49-56.

https://doi.org/10.4236/jbnb.2021.124005

Received: July 15, 2021

Accepted: August 14, 2021

Published: August 17, 2021

Copyright (C) 2021 by author(s) and Scientific Research Publishing Inc. This work is licensed under the Creative Commons Attribution International License (CC BY 4.0).

http://creativecommons.org/licenses/by/4.0/

\begin{abstract}
In this study, we aimed to use a novel approach to overcome the current limitations of ozone therapy in medicine through ozonized oil nanoemulsions (OZNEs). We evaluated dose-dependency on the cellular activities of B-16 melanoma cell line which were incubated with various OZNE doses $(\mathrm{v} / \mathrm{v})$. Antitumor effects of OZNE against cancer cell lines were evaluated by cellular morphology, apoptosis and cell cycle analysis. Flow cytometry results showed that OZNE induced DNA damage, apoptosis, and arrested cell cycle in G0-1 phase in B-16 melanoma cells. Thus, OZNE treatment could pose an effective way to act as a potential therapeutic for patients with tumors in the future.
\end{abstract}

\section{Keywords}

Ozonized Oil, Nanoemulsion, B-16 Melanoma, Cancer

\section{Introduction}

Despite the development of advanced imaging and treatment techniques, cancer significantly reduces survival and quality of life. The most important factor limiting treatment success, especially in radiotherapy and chemotherapy, is tumor hypoxia [1]. In the presence of tumor hypoxia, the resistance to treatment and the risk of metastasis increase [2] [3] [4], as well as shortening survival and disease-free survival [5].

Ozonized oil (ozone enriched oil form), which is formed as a result of the reaction of ozone with vegetable oils, is preferred due to the difficulties of ozone during its application (i.e. high reactivity of ozone gas, low solubility, and low absorption) [6] [7]. In recent years, ozonized oil is launched as an effective therapeutic agent for medical applications. However, ozone oil applications in medi- 
cine are still challenging since ozone affects the intracellular signaling system with compounds formed by unsaturated fatty acids [7]. Thus, there is currently no established consensus on the best routes to proceed for ozonized oil and cancer treatment approaches.

In this study, we aimed to investigate the effects of ozonized oil nanoemulsions on cancer cells to better understand alternative cancer treatment approaches via ozone. Nanoemulsions are thermodynamically unstable systems [8], and depending on their small droplet size and large surface area, they have superior drug transport and penetration capabilities [9]. Moreover, nanoemulsions protect active ingredients against physicochemical stress, and their drug efficacy is high in oral or intravenous drug applications [10] [11] [12]. Due to these properties, they are frequently used in cosmetics; pharmaceutical industry and dermatology are very promising for future cancer treatments [9]. To the best of our knowledge, this is the first study that investigates the cellular activities of B-16 melanoma cancer cell line treated with ozonized oil nanoemulsions. This is significant because the effects of hypoxia and the therapeutic activity of oxygenation in cancer cells with regard to ozone are still challenging. Thus, the study was designed to investigate in vitro cellular activities of ozonized oil nanoemulsions treated with B-16 melanoma due to the key dose parameters. In this regard, B-16 melanoma cells were incubated with ozonized oil nanoemulsions at different concentrations (Figure 1). Then, in vitro cellular activities of B-16 melanoma cells have been evaluated by cellular morphology, apoptosis, cell cycle analysis and DNA damage/repair.

\section{Materials and Methods}

Nanoemulsions were prepared using Ozonized oil (Aktifoks Ozonid, Izmir, Turkey) by the emulsion inversion point (EIP) low-energy method as described in our previous study [13]. In this study, size distribution and zeta potential of nanoemulsions were analyzed through dynamic light scattering (DLS) with Zetasizer Nano-S (Malvern, England) (data not shown, average particle size: $212 \mathrm{~nm}$, zeta potential: $-22.5 \mathrm{mV}$ ). Malignant melanoma mouse B-16 cell line has been obtained from ATCC (Germany). All the other chemicals (Sigma-Aldrich, Germany) were analytical grade and used without further purification.

\subsection{In Vitro Cell Culture Studies}

B-16 mouse melanoma (B16, ATCC CRL-6475) cells was cultured in RPMI 1640
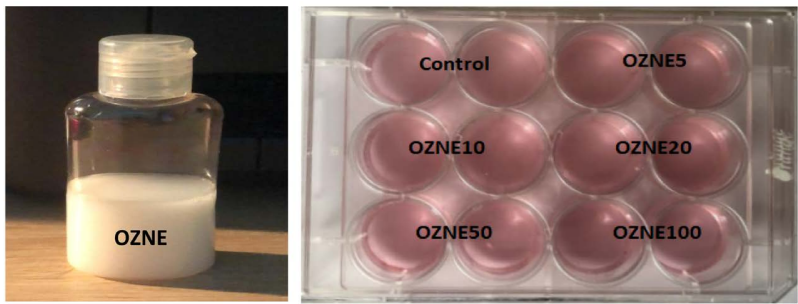

Figure 1. Ozonized oil nanoemulsion (OZNE) treated w/wo B-16 melanoma cells. 
medium (Sigma, Germany) supplemented with $10 \%$ fetal calf serum (FCS, (Sigma, Germany), 10\% L-glutamine (Sigma, Germany) and 10\% penicillin/streptomycin (Sigma, Germany). The cells were passaged with $0.25 \%$ trypsin-EDTA when confluent layer was observed under inverted microscopy. Throughout this study, cells were maintained at $37^{\circ} \mathrm{C}$ in a humidified $\mathrm{CO}_{2}(5 \%)$ atmosphere (Heraeus Instruments, Germany). All tissue culture components used in this study were obtained from Sigma (Germany), unless otherwise described.

\subsection{Cell Seeding and Microscopic Imaging}

Cell culture studies were conducted in sterile 12-well tissue culture polystyrene (TCPS) dishes in stationary conditions. In brief, $2 \mathrm{~mL}$ of cell suspension (RPMI 1640 supplemented with 10\% FBS (and 10\% penicillin-streptomycin) at a density of $5 \times 10^{5}$ cells $\mathrm{mL}^{-1}$ was seeded in 12 -well plates. After 3 days of incubation, B-16 melanoma cells were incubated with ozonized oil nanoemulsion (OZNE) groups which were filtered by $0.22 \mu \mathrm{m}$ filter (Milipore, Sigma) ((control group A, without OZNE), (OZNE5, group B, $5 \mu \mathrm{L} /$ well), (OZNE10 group C, $10 \mu \mathrm{L} /$ well), (OZNE20, group D, $20 \mu \mathrm{L} /$ well), (OZNE50, group E, $50 \mu \mathrm{L} /$ well), and (OZNE100, group F, $100 \mu \mathrm{L} /$ well $),(1 \mu \mathrm{L}$ OZNE dose $=0.015 \mu \mathrm{L}$ ozonized oil) $)$ for $60 \mathrm{~min}$ at $37^{\circ} \mathrm{C}$. For microscopy, B-16 melanoma cells were imaged by an inverted microscope (Nikon, Japan).

\subsection{Cell Cycle and DNA Analysis}

B-16 melanoma cells treated with all OZNE groups were detached with $0.25 \%$ trypsin-EDTA, centrifuged, washed 3 times, and resuspended in cold RPMI 1640. The ready-made solution which includes RNAase and saponin and propidium iodide (PI) was added (according to the manufacturer's instructions (Sigma, Germany)) and they all kept in the dark and room temperature for $20 \mathrm{mi}$ nutes. Flow cytometer (Beckman Coulter, FL) was used to analyze the cell-associated fluorescence. DNA analysis has been evaluated with MultyCycleCXP 2.2. (Beckman Coulter, FL).

\subsection{Annexin V Apoptosis Study}

B-16 melanoma cells treated with all OZNE groups supplemented with Annexin V (5 $\mu \mathrm{L}$, (Sigma, Germany)) and PI (10 $\mu \mathrm{L}$, (Sigma, Germany)) were kept in the dark and room temperature for 15 minutes. Cell apoptosis was investigated using flow cytometry (Beckman Coulter, FL). We used the Annexin V apoptosis kit according to the manufacturer's instructions (Sigma, Germany). Annexin V-PI negative cells have been evaluated as viable, both positive ones were late apoptotic/necrotic, only those with Annexin $\mathrm{V}$ positive as early apoptotic.

\section{Results and Discussion}

\subsection{The Effect of OZNE Concentration on Cellular Morphology}

B-16 melanoma cells incubated in the presence of all OZNE groups and control 
groups (without nanoemulsions) observed under an inverted microscope at the end of 1 hour and the images were demonstrated in Figure 2. The morphologies of cells, exposed to all OZNE groups, started to change compared to control cells. Severe fractures were observed, even at low concentrations the morphologies of cells are changed (Figure 2).

It is noteworthy that the cellular interaction between each other decreases especially for cells treated with OZNE groups (Figures 2(D)-(F)). Moreover, clustered cells incubated with the OZNE100 group (Figure 2(F)) greatly disappeared and destructed. These significant changes in the morphologies of cells incubated with OZNE groups, which leads a severe decrease of cellular viabilities, may indicate OZNE as an anticancer agent for B-16 melanoma cells. Results concluded that OZNE concentration should be concerned with regard to the treatment of B-16 melanoma cells.

\subsection{Cell Cycle Analysis, DNA Synthesis and Apoptosis}

The cell cycle analysis in cancer cell lines always indicates a high cell proliferation rate. Using flow cytometry for cell cycle analysis is a useful technique for
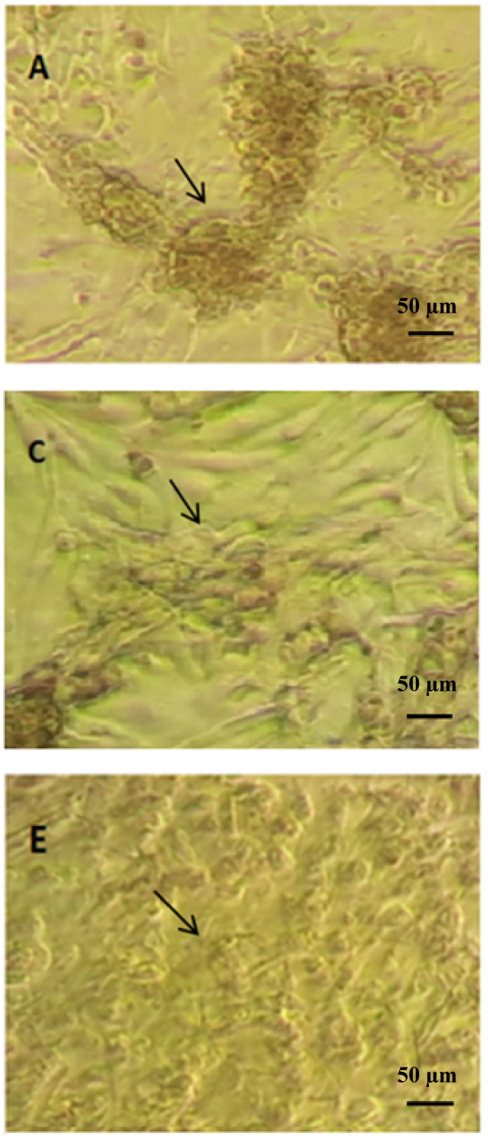
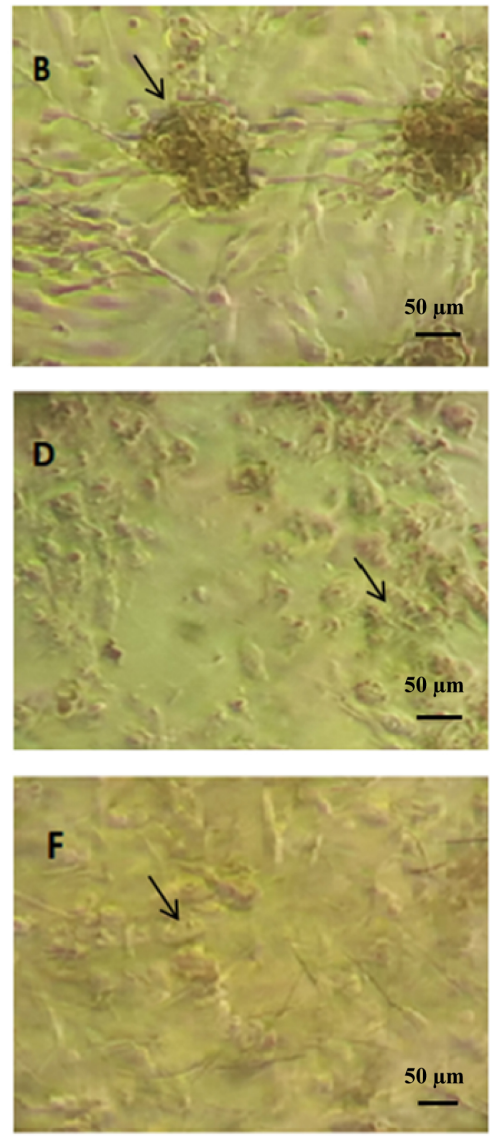

Figure 2. Inverted microscope images of B-16 melanoma cells treated with different concentrations of ozonized oil nanoemulsion; (A) Control, (B) OZNE5, (C) OZNE10, (D) OZNE20, (E) OZNE50, (F) OZNE100. Original magnifications 200X. Scale bar $=50$ mmmicrometer ( ${ }^{\oplus}$ cell clusters). 
anticancer research. In order to determine the effect of ozonized oil nanoemulsion on cell cycle progression of B-16 melanoma cells, OZNE treated and untreated B-16 cells were stained with PI and analyzed by flow cytometry, and the results were demonstrated in Figure 3(A). As seen from Figure 3(A), the percentage of cells in the G0-1 phase increased from $57.7 \%$ to $76.4 \%$ with regard to the increase in OZNE concentration. Moreover, the percentage of cells in the $S$ phase gradually decreased (from $22.8 \%$ to $7.4 \%$ ) due to the increase in OZNE concentration. The treatment of OZNE significantly increased cells arrested in the G0-1 compared to control groups ( 1.5 -fold) and decreased cells arrested in S-phase compared to untreated cells ( 3-fold). Moreover, the narrow and distinct shaped peaks after OZNE20 nanoemulsion treatment were determined (Figures 3(A)-(d)-(f)) which may be due to the fact that OZNE concentration greatly inhibited DNA synthesis and B-16 melanoma cells were suppressed by ozonized oil nanoemulsions. These results are consistent with previous studies [14] [15]. In the study conducted by Li et al. with curcumin in the MCF-7 breast cancer cell line, the cell cycle has been affected in the G1 phase [16]. Meghani et al. have tested the anticancer effect of cinnamon oil nanoemulsion loaded cinnamon oil and vitamin D on A549 lung cancer [17]. Various concentrations $(400 \mu \mathrm{g} / \mathrm{mL}$ and $600 \mu \mathrm{g} / \mathrm{mL})$ of cinnamon oil have been observed to cause cell cycle arrest in the G0-1 phase. G0-1 phase is the same as both nanoemulsion

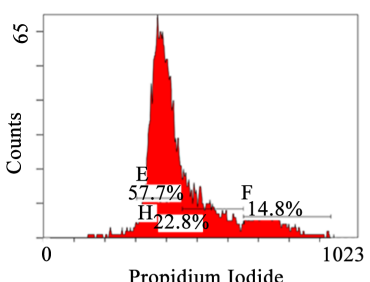

(a)

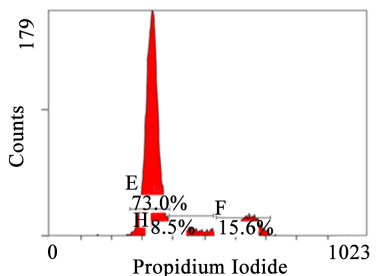

(d)

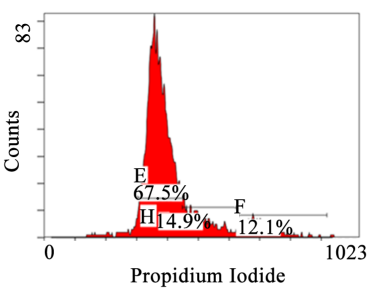

(b)

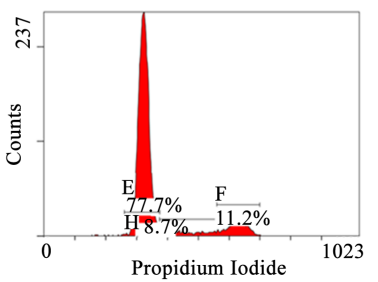

(e)

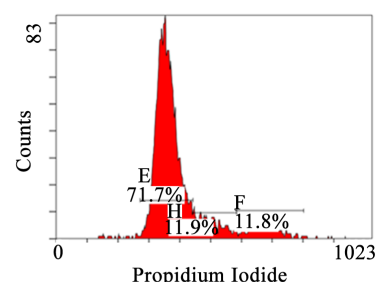

(c)

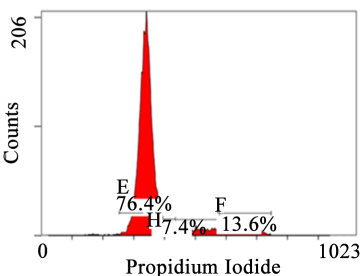

(f)

(A)

\begin{tabular}{lcccccc} 
Annexin-V analysis & Control & OZNE5 & OZNE10 & OZNE20 & OZNE50 & OZNE100 \\
\hline $\begin{array}{l}\text { Annexin-V+/PI+ } \\
\text { quadrant }\end{array}$ & $2.8 \%$ & $5.7 \%$ & $2.3 \%$ & $1.8 \%$ & $2.4 \%$ & $14.2 \%$ \\
\hline Annexin-V+ quadrant & $0.2 \%$ & $0.1 \%$ & $0.1 \%$ & $0.0 \%$ & $0.4 \%$ & $1.7 \%$ \\
\hline
\end{tabular}

(B)

Figure 3. (A) Cell cycle distribution of B-16 melanoma cells treated with different concentrations of ozonized oil nanoemulsion; (a) Control (b) OZNE5, (c) OZNE10, (d) OZNE20, (e) OZNE50, (f) OZNE100. (Notation in the histograms; $E=$ G0-1 phase, $\mathrm{H}=\mathrm{S}$ phase, $\mathrm{F}=\mathrm{G} 2-\mathrm{M}$ phase). (B) Quantification of Annexin-V analysis: Late Apoptosis (annexin-V+/PI+ quadrant), Early apoptosis (annexin-V+ quadrant). 
(76\%) at $400 \mu \mathrm{g} / \mathrm{mL}$ concentration. But maximum arrest (83.74\%) observed at concentration $600 \mu \mathrm{g} / \mathrm{mL}$ of vitamin $\mathrm{D}$ encapsulated cinnamon oil nanoemulsion. Especially the effectiveness of nanoemulsion form is clearer at high concentration [17].

In order to evaluate apoptotic B-16 melanoma cell populations treated with OZNE nanoemulsions, Annexin-V study was performed by flow cytometry. Quantification of Annexin-V analysis showed a significant increase in apoptotic cell populations when treated with OZNE100 groups ( $\sim$-fold) (Figure 3(B)). Cell population increase in the annexin-V+/PI+ quadrant, indicating late apoptosis, was detected from $2.8 \%$ in control cells to $14.2 \%$ in the OZNE100 group. Moreover, B-16 melanoma cells displayed an early apoptotic population increase from $0.2 \%$ in control cells to $1.7 \%$ in OZNE100 treatment.

Monge-Fuentes et al. studied the efficacy of acai oil nanoemulsion form in $\mathrm{NIH} / 3 \mathrm{~T} 3$ mouse fibroblast and B16F10 mouse melanoma cell line, and reported that acacia nanoemulsion induced late apoptosis in the B16F10 cell line but has not caused a change in the NIH/3T3 cell line [18]. In another study, Chiani et al. investigated the effect of different concentration cisplatin and Cisplatin loaded nanoparticles on the A172 cell line. Results indicated that cisplatin nanoparticle increases early and late apoptosis compared to free cisplatin by using flow cytometry technique. Also, cisplatin loaded nanoparticles in all concentration were more efficient and cytotoxic than a free form of cisplatin for A172 cancer cell line [19]. Janic et al. showed the apoptosis of THP-I cells when exposed to different concentrations $(0.1-0.5 \mathrm{ppm}$ for $1 \mathrm{~h})$ of ozone by comparing it with filtered air. Cell viability decreased in ozone exposure (5\% - 17\%). The percentage of dead cells right after exposure to ozone was higher as compared to filtered air, but there was no difference after 24 hours and 72 hours. At $1 \mathrm{~h}$ and $3 \mathrm{~h}$ after exposure to ozone, as a result of the measurements taken at different time intervals, there has been a higher increase in early and late apoptosis values in the group that ozone was applied in the first 3 hours [20]. Our findings provide a promising therapeutic method to eliminate cancer cells. However, further studies should be done by performing in vivo tests in order to fully prove the mechanism of the OZNE effect which has not yet been fully elucidated.

\section{Conclusion}

In this study, ozonized oil nanoemulsion effect in B-16 melanoma cell line along with the possible mechanism underlying, cell cycle, DNA synthesis and damage, and apoptosis behavior was explored for the first time. Our data on OZNE nanoemulsion suggest, apart from traditional medicinal treatment, within the knowledge of new sources can be developed that are safe and efficient. Here, we identified possible OZNE nanoemulsion treatment in a concentration-dependent manner. The occurrence of DNA damage was correlated with cell a cycle arrest in G0/G1 phase and results suggest that a high concentration of OZNE nanoemulsion induced apoptosis in B-16 melanoma cells. However, it is noteworthy to 
mention that further study would be required to fully understand the impact of reactive oxygen species (ROS) levels and the mechanism of cellular damage in DNA structure, regarding the ozonized oil nanoemulsions studied here. Thus, future studies of OZNE nanoemulsion may further support its use in therapeutic applications for cancer due to the mechanism regarding cellular death which leads to ozonized oil nanoemulsions will become a target in cancer therapy.

\section{Acknowledgements}

This study was financially supported by Builent Ecevit University Scientific Research Projects, Project No. 2016-39971044-02.

\section{Conflicts of Interest}

The authors declare no conflicts of interest regarding the publication of this paper.

\section{References}

[1] Höckel, M. and Vaupel, P. (2001) Biological Consequences of Tumor Hypoxia. Seminars in Oncology, 28, 36-41. https://doi.org/10.1016/S0093-7754(01)90211-8

[2] Mimeault, M. and Batra, S.K. (2013) Hypoxia-Inducing Factors as Master Regulators of Stemness Properties and Altered Metabolism of Cancer- and Metastasis-Initiating Cells. Journal of Cellular and Molecular Medicine, 17, 30-54. https://doi.org/10.1111/jcmm.12004

[3] Yun, Z. and Lin, Q. (2014) Hypoxia and Regulation of Cancer Cell Stemness. Advances in Experimental Medicine and Biology, 772, 41-53. https://doi.org/10.1007/978-1-4614-5915-6_2

[4] Plasswilm, L., Tannapfel, A., Cordes, N., Demir, R., Hoeper, K., Bauer, J. and Hoeper, J. (2000) Hypoxia-Induced Tumour Cell Migration in an in Vivo Chicken Model. Pathobiology, 68, 99-105. https://doi.org/10.1159/000055909

[5] Rankin, E.B. and Giaccia, A. (2016) Hypoxic Control of Metastasis. Science, 352, 175-180. https://doi.org/10.1126/science.aaf4405

[6] Serio, F., Pizzolante, G., Cozzolino, G., D’Alba, M., Bagordo, F., De Giorgi, M., Grassi, T., Idolo, A., Guido, M. and De Donno, A. (2017) A New Formulation Based on Ozonated Sunflower Seed Oil: In Vitro Antibacterial and Safety Evaluation. Ozone: Science Engineering, 39, 139-147. https://doi.org/10.1080/01919512.2016.1272405

[7] Travagli, V., Zanardi, I., Valacchi, G. and Bocci, V. (2010) Ozone and Ozonated Oils in Skin Diseases: A Review. Mediators of Inflammation, 2010, Article ID: 610418. https://doi.org/10.1155/2010/610418

[8] Komaiko, J.S. and McClements, D.J. (2016) Formation of Food-Grade Nanoemulsions Using Low-Energy Preparation Methods: A Review of Available Methods. Comprehensive Reviews in Food Science and Food Safety, 15, 331-352. https://doi.org/10.1111/1541-4337.12189

[9] Shah, P., Bhalodia, D. and Shelat, P. (2010) Nanoemulsion: A Pharmaceutical Review. Systematic Reviews in Pharmacy, 1, 24-32. https://doi.org/10.4103/0975-8453.59509

[10] Periasamy, V.S., Athinarayanan, J. and Alshatwi, A.A. (2016) Anticancer Activity of an Ultrasonic Nanoemulsion Formulation of Nigella sativa L. Essential Oil on $\mathrm{Hu}-$ 
man Breast Cancer Cells. UItrasonicssonochemistry, 31, 449-455.

[11] Tadros, T., Izquierdo, P., Esquena, J. and Solans, C. (2004) Formation and Stability of Nano-Emulsions. Advances in Colloid Interface Science, 108, 303-318. https://doi.org/10.1016/j.cis.2003.10.023

[12] Jaiswal, M., Dudhe, R. and Sharma, P. (2015) Nanoemulsion: An Advanced Mode of Drug Delivery System. 3 Biotech, 5, 123-127. https://doi.org/10.1007/s13205-014-0214-0

[13] TığlıAydın, R.S. and Kazancı, F. (2018) Synthesis and Characterization of Ozonated Oil Nanoemulsions. Journal of the American Oil Chemists' Society, 95, 1385-1398. https://doi.org/10.1002/aocs.12150

[14] Patel, P.B., Thakkar, V.R. and Patel, J.S. (2015) Cellular Effect of Curcumin and Citral Combination on Breast Cancer Cells: Induction of Apoptosis and Cell Cycle Arrest. Journal of Breast Cancer, 18, 225-234. https://doi.org/10.4048/jbc.2015.18.3.225

[15] Milacic, V., Banerjee, S., Landis-Piwowar, K.R., Sarkar, F.H., Majumdar, A.P. and Dou, Q.P. (2008) Curcumin Inhibits the Proteasome Activity in Human Colon Cancer Cells in Vitro and in Vivo. Cancer Research, 68, 7283-7292.

https://doi.org/10.1158/0008-5472.CAN-07-6246

[16] Li, H.-Q., Jin, L.-J., Wu, F.-F., Li, X.-Y., You, J.-S., Cao, Z.-H., Li, D. and Xu, Y.-P. (2012) Effect of Curcumin on Proliferation, Cell Cycle, and Caspases and MCF-7 Cells. African Journal of Pharmacy Pharmacology, 6, 864-870.

[17] Meghani, N., Patel, P., Kansara, K., Ranjan, S., Dasgupta, N., Ramalingam, C. and Kumar, A. (2018) Formulation of Vitamin D Encapsulated Cinnamon Oil Nanoemulsion: Its Potential Anti-Cancerous Activity in Human Alveolar Carcinoma Cells. Colloids Surfaces B: Biointerfaces, 166, 349-357. https://doi.org/10.1016/j.colsurfb.2018.03.041

[18] Monge-Fuentes, V., Muehlmann, L.A., Longo, J.P.F., Silva, J.R., Fascineli, M.L., de Souza, P., Faria, F., Degterev, I.A., Rodriguez, A. and Carneiro, F.P. (2017) Photodynamic Therapy Mediated by Acai Oil (Euterpe oleracea Martius) in Nanoemulsion: A Potential Treatment for Melanoma. Journal of Photochemistry Photobiology B: Biology, 166, 301-310. https://doi.org/10.1016/j.jphotobiol.2016.12.002

[19] Chiani, M., Toofani Milani, A., Nemati, M., Rezaeidian, J., Ehsanbakhsh, H., Ahmadi, Z., Mazloomi, E., Sadeghi, V. and AkbarzadehKhiyavi, A. (2019) Anticancer Effect of Cisplatin-Loaded Poly (Butylcyanoacrylate) Nanoparticles on A172 Brain Cancer Cells Line. Asian Pacific Journal of Cancer Prevention: APJCP, 20, 303-309. https://doi.org/10.31557/APJCP.2019.20.1.303

[20] Janic, B., Umstead, T.M., Phelps, D.S. and Floros, J. (2003) An in Vitro Cell Model System for the Study of the Effects of Ozone and Other Gaseous Agents on Phagocytic Cells. Journal of Immunological Methods, 272, 125-134.

https://doi.org/10.1016/S0022-1759(02)00440-4 